\title{
Status of Fisheries Resources of Honda Bay (2003-2013)
}

\author{
Myrna B. Candelario ${ }^{1, \star}$, Lenie M. Gonzales ${ }^{1}$, Jeanette A. Jardin ${ }^{1}$ \\ ${ }^{1}$ Department of Agriculture, Bureau of Fisheries and Aquatic Resources - MIMAROPA, \\ Inland Sea Ranching Station, Sta. Monica, Puerto Princesa City, 5300 Palawan, Philippines
}

\section{A B S T R A C T}

This paper discusses the status of fisheries resources of Honda Bay from January 2003 to December 2013. The eleven years annual production data shows a fluctuating trend. There was an increase in the annual number of boat landings of all gear from 95,284 in 2003 to 259,383 in 2011. The highest production was recorded in 2010 with 2,761.83 MT and the lowest in 2007 with 1,555.94 MT. Municipal fisheries contribute a large share of production with $86.03 \%$ dominated by Leoignathus splendens with $9.58 \%$, while commercial fisheries share $13.97 \%$ dominated by Amblygaster sirm which shares 38.95\%. The seasonality of fishing operation for municipal fisheries is not pronounced as almost all of the different gears surveyed operate year-round, while the trend of production for commercial fishing operation is influenced by southeast monsoon or "habagat" and northeast monsoon or "amihan". Selar crumenopthalmus and Rastrelliger kanagurta exhibited only one pulse per year while the Siganus canaliculatus and Lethrinus miniatus showed two pulses per year. Population parameter estimates showed that of the 10 species analyzed $93 \%$ have an exploitation ratio above 0.5 , which means that a majority of the common species caught were beyond their regenerative capacity.

*E-mail: mbcandz_01@yahoo.com

Received: 12 May 2017

Accepted: 4 September 2017
Keywords: Honda Bay, Fisheries Resources, Overfishing, CPUE, Exploitation

\section{I N T R O D UCT I O N}

$\mathbf{F}$ isheries resources were naturally consumable, renewable but finite with some of the species already extinct, vulnerable and endangered which needs more attention and action (Hermes 1998). Fisheries information such as updated and valid biological, capture and biodiversity status of major species is a vital key in formulating guidelines to protect, conserve, develop and manage Philippine marine fisheries resources. Thus, resource assessment is necessary to conduct in all prospect sites in the country particularly those situated in highly diverse areas such as Palawan. In response, the National Government through the Bureau of Fisheries and Aquatic Resources (BFAR) implemented the National Stock Assessment Program (NSAP) in all regional offices.

Honda Bay is one of the major fishing grounds within West Sulu Sea. It lies within $100 \mathrm{~km}$ coastal stretch and consists of 18 coastal barangays. The bay covers an area of 81.63 sq. nautical miles with 12 chartered islands. The semi-enclosed waters of the bay are economically and ecologically important, with numerous marine species being nurtured in its lagoons and estuaries. Although other resources such as mangroves, corals, seagrass, and invertebrates are categorized as being fair and moderate in condition, the bay shows signs of deterioration of its fish resources and ecosystems (Gonzales 2004).

With consideration of the population density vis-a-vis the status of the bay, Fox (1986) categorized Honda bay as "lightly fished" area with fisher density of 3 fishers $\mathrm{km}^{-1}$. In the study conducted by LachicaAliño (2001), they recorded as high as 26 fishers $\mathrm{km}^{-1}$ of coastline. This figure classified Honda Bay as moderately fished area based on the definition of Fox (1986) of a moderately exploited area as those with 20-70 fishers $\mathrm{km}^{-1}$ of coastline. However, in the study conducted by Ramos et al. (2009), fishers $\mathrm{km}^{-1}$ of coastline was decreased to 17 fishers. On the other hand, the average catch per trip on previous studies conducted shows a significant decrease from $36.5 \mathrm{~kg}$ to $5 \mathrm{~kg}$.

This paper discusses the results of eleven years (2003-2013) assessment in Honda Bay as a continuation and updated version of the Technical Paper Series "The Honda Bay Fisheries: An Assessment" published by BFAR-NFRDI in 2009.

\section{Objectives of the Study}

Generally, the objective of this study is to generate reliable information in addition to the previous studies as a basis for the formulation of policies towards the development, conservation, and management of the country's marine resources.

Specifically, it aims to determine the following:

a. Current level of production;

b. Species composition, effort and CPUE by gear of fish and invertebrate species of the bay; 


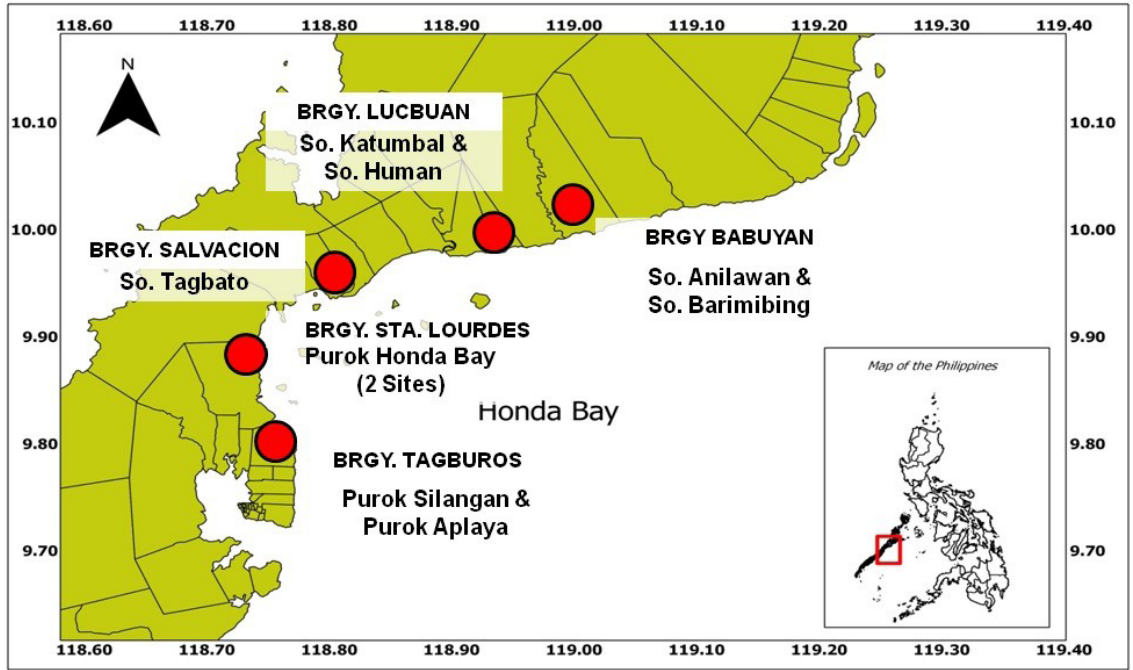

Figure 1. Map showing the location of fish landing sites/sampling areas at Honda Bay.

c. Estimate of growth, mortality, exploitation ratio and recruitment pulses of dominant species; and

d. Abundance and seasonality of dominant species.

\section{MATERIALS AND METHODS}

There were nine fish landing sites established for the implementation of the Fish Stock Assessment of Honda Bay. It was located in Bgy. Tagburos (Purok Aplaya and Purok Silangan), Bgy. Sta. Lourdes (Purok Honda Bay Sites, Commercial and Municipal), Bgy. Salvacion (Sitio Tagbato), Bgy. Lucbuan (Sitio Human and Sitio Katumbal), and Bgy. Babuyan (Sitio Anilawan and Sitio Barimbing) in Puerto Princesa City (Figure1).

Sampling sites were monitored every two days regardless of Saturdays, Sundays, and holidays. Two enumerators were assigned to each landing sites to collect data on the total boat catch by species and by gear type, length measurement, and other pertinent information.

An inventory of fishing boats and gears was done yearly to determine the number of motorized and non-motorized boats and gear used. This was conducted in 18 coastal barangays in coordination with Barangay officials.

The effort and Catch per Unit of Effort (CPUE) of all gears were standardized using Bottom Gill Net (BGN) units. To determine the annual effort in terms of the number of boat landings of BGN, the annual estimated yield was divided by the annual CPUE of BGN.

The length frequencies of the common species were analyzed by gear to determine what type of fishing gear is catching a high percentage of immature or smallsized fishes. FishBase and some recent literature were used as a reference for the length $(\mathrm{cm})$ at first maturity (Lm) of the species analyzed.

The population parameters of the common species were estimated using the FAO-ICLARM Stock Assessment Tool or FiSAT (Gayanillo et al., 1996). This tool was also used to analyze the length frequency data of the common fish species in Honda Bay. The computed population parameters are needed to determine the recruitment patterns, mortality estimation, and exploitation rate $(\mathrm{E})$ of common species.

\section{RES ULT S}

\section{Overview of the Study Area}

Honda Bay is known for its rich coral reef areas, fishes, and beautiful islands. The bay is considered as one of the major fishing grounds in the northeastern side of Palawan that lies within the West Sulu Sea with about 28,000 nautical miles. It consists of 18 coastal barangays and numerous islands interspersed, all of which are encircled by fringing reefs with extensive reef flats. Among those islands, Fondeado Island (41 ha) is the largest and the smallest is the Canon Island (31.25 ha). There are eight main rivers that carry clean water and some industrial waste in the bay namely Babuyan, Bacungan, Langogan, Magarwak, Tanabag, Tandayak, Tarabanan, and Ulanguan (Gonzales 2003).

\section{Management Interventions}

Palawan was considered as the Fish Bowl of the Philippines because of the richness of the province in terms of marine biodiversity. However, Honda Bay is now experiencing continues decline in stock and destruction of marine habitat because of over and destructive fishing, intrusion of fishers into the fish sanctuaries, and deterioration of coastal water quality (PCSD 2008).

Based on Puerto Princesa City Ordinance No. 163 (2004), the coastal communities, fishermen from different municipalities of Palawan and some from different provinces put too much pressure in Honda Bay by using an obnoxious substance and blast fishing methods. In order to recover, the City government in collaboration with BFAR, NGO's, PO's, Academe, and law Enforcers established eight marine sanctuaries, two 
Table 1 . Mean length and sizes at $1^{\text {st }}$ maturity of dominant species caught by different gear

\begin{tabular}{|c|c|c|c|}
\hline Species & Gear & Mean Length $(\mathrm{cm})$ & Size at $1^{\text {st }}$ Maturity $(\mathrm{cm})$ \\
\hline \multirow[t]{3}{*}{ Atule mate } & $\mathrm{RN}$ & 19.63 & \multirow[t]{3}{*}{16.9} \\
\hline & $\mathrm{BGN}$ & 21.73 & \\
\hline & $\mathrm{FC}$ & 13.82 & \\
\hline \multirow[t]{3}{*}{ Lutjanus fulviflammus } & $\mathrm{BGN}$ & 18.75 & \multirow[t]{3}{*}{18.7} \\
\hline & $\mathrm{FC}$ & 18.84 & \\
\hline & BSLL & 19.40 & \\
\hline \multirow[t]{3}{*}{ Lutjanus vita } & $\mathrm{BGN}$ & 19.08 & \multirow[t]{3}{*}{15.4} \\
\hline & BSLL & 19.03 & \\
\hline & $\mathrm{FC}$ & 18.79 & \\
\hline \multirow[t]{3}{*}{ Nemipterus furcosus } & MHL & 19.49 & \multirow[t]{3}{*}{16.0} \\
\hline & BGN & 20.52 & \\
\hline & BSLL & 19.57 & \\
\hline \multirow[t]{3}{*}{ Nemipterus hexodon } & $\mathrm{MHL}$ & 17.28 & \multirow[t]{3}{*}{15.3} \\
\hline & BGN & 18.72 & \\
\hline & BSLL & 18.24 & \\
\hline \multirow[t]{3}{*}{ Pentapodus caninus } & BGN & 19.51 & \multirow[t]{3}{*}{21.2} \\
\hline & $\mathrm{FC}$ & 16.99 & \\
\hline & BSLL & 19.79 & \\
\hline \multirow[t]{3}{*}{ Rastrelliger kanagurta } & $\mathrm{RN}$ & 20.34 & \multirow[t]{3}{*}{19.9} \\
\hline & BGN & 24.33 & \\
\hline & $\mathrm{FC}$ & 17.86 & \\
\hline \multirow[t]{3}{*}{ Selar boops } & BGN & 19.19 & \multirow[t]{3}{*}{17.2} \\
\hline & $\mathrm{FC}$ & 18.35 & \\
\hline & EGN & 17.46 & \\
\hline \multirow[t]{3}{*}{ Selar crumenophthalmus } & $\mathrm{RN}$ & 20.09 & \multirow[t]{3}{*}{19.75} \\
\hline & BGN & 19.16 & \\
\hline & SLN & 17.33 & \\
\hline \multirow[t]{3}{*}{ Siganus canaliculatus } & $\mathrm{BGN}$ & 16.65 & \multirow[t]{3}{*}{18.75} \\
\hline & $\mathrm{FC}$ & 16.75 & \\
\hline & EGN & 16.28 & \\
\hline
\end{tabular}

fish sanctuaries, and one environmental park in strategic areas along Honda Bay that covers about 1997.72 ha. The coastal community that relies in the area that had become protected were given alternative livelihood such as seaweed culture, tilapia culture, fish cage culture of green grouper, bangus culture, sea cucumber culture, gillnet mending/construction, fish processing, valueadding such as smoked-fish, fish lamayo, fish embutido, fish fillet, fish longganisa, bangus deboning, and seaweed processing (seaweed yema, noodles, and pickles).

\section{Fishery Demographics}

Based on the data gathered by enumerators in 2013, there are a total of 1,300 fishermen living near the coastal area of Honda Bay with Bgy. Babuyan (209 fishers) and Tagburos (175 fishers) having the most number; while Bgy. Maoyon had the least recorded. The average density of fishermen in the bay is 13 fisher $\mathrm{km}^{-1}$ with Bgy. Tagburos $\left(34 \mathrm{~km}^{-1}\right)$ having the highest density followed by Bgy. San Manuel and San Jose (both $18 \mathrm{~km}^{-1}$ ) and the lowest was Bgy. Sta. Lourdes $\left(5 \mathrm{~km}^{-1}\right)$. This index was not applicable in Bgy. Maoyon since the area is landlocked. Fishermen from this area share the coastline of Barangays Lucbuan and Babuyan with a high-density value of $36 \mathrm{~km}^{-1}$ (Figure 2). A typical fisher in the bay supports a household of five and most of them have their own

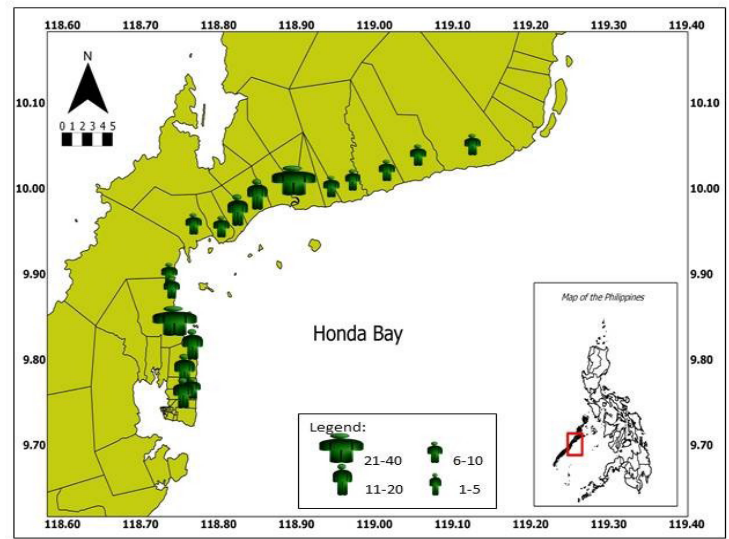

Figure 2. Density of Fishermen per barangay along Honda bay 2003 to 2013 .

motorized boats with at least two fishing gears (Ramos et al. 1999). Almost all of the fishermen are full-time, entirely dependent on the marine resources of the bay as their main source of income while others were engaged in other income-generating activities such as boat operation for tourism activities, construction, carpentry works, and farming, among others. 


\section{Boats and Gears}

In the span of 10 years, the number of boats increased by $58 \%$ from 505 in 2003 to 872 in 2013 (58\% of these boats are motorized and $42 \%$ are non-motorized). Majority of these non-motorized boats were used in the gathering of octopus, the fourth most dominant among the ten major species caught by municipal fisheries (Figure 3).

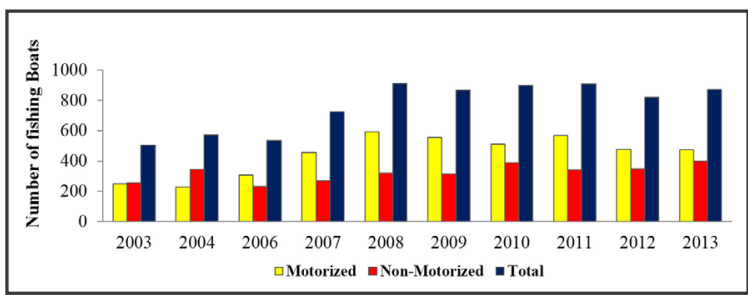

Figure 3. Number fishing boats (motorized and non-motorized) in Honda Bay from 2003 to 2013.

On the other hand, fishermen used 22 kinds of gears that vary from nets, lines, traps/barriers, and hand instrument. An increasing trend in the number of gears operating within the municipal water was recorded with 691 in 2003 and 1,117 in 2013. As such, the catches landed by a fishing boat came from two or more fishing gear. Consistent for 10 years, lines are the major gear used in the area composed of bottom set long line (BSLL), hook and line (HL), multiple hook and line (MHL), and troll line (TL) as can be seen in Figure 4.

In 2005, no actual inventory on boat and gear was conducted, thus the data for 2004 were used as the basis for the estimation of effort.

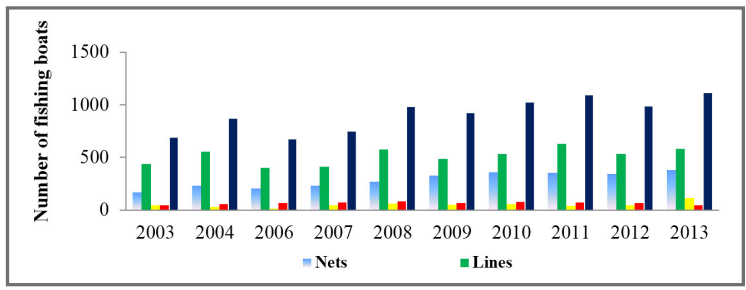

Figure 4. Number of gear per category from 2003 to 2013.

\section{Annual production}

The annual production of the bay showed a fluctuating trend from 2003 to 2013. This ranged from $1,555,941.40 \mathrm{~kg}$ in 2007 to $2,761,827.35 \mathrm{~kg}$ in 2010 (Figure 5). Fluctuations in the production were attributed to the irregular operation of ring net. It was observed that this commercial fishing gear operates within the bay despite the implementation of the law banning the use of active gears within the $15-\mathrm{km}$ municipal waters (RA \#8550, Section 90). However, in 2009 the said gear eventually stop its operation and transferred to other fishing ground.

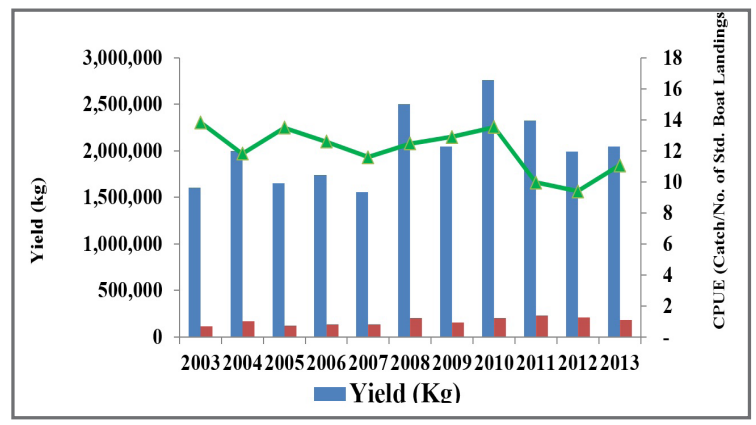

Figure 5. Catch and effort relationship in Honda Bay from 2003 to 2013 .

\section{Effort and Catch per Unit Effort}

The number of boat landings using standardized BGN unit ranges from 116,077 in 2003 to 233,377 in 2011. This shows that the increase in boat landings contributes only to the increase in production but with low CPUE.

The CPUE ranges from $9.39 \mathrm{~kg} /$ boat in 2012 to $13.84 \mathrm{~kg} /$ boat in 2003. It fluctuates over the years but no significant increase or decrease is observed.

Data on seven years CPUE of commercial fisheries, particularly the ring net which is the only commercial gear, shows a fluctuating trend from 2003 to 2007 and a significant decrease in 2008 to 2009 (Figure 6).

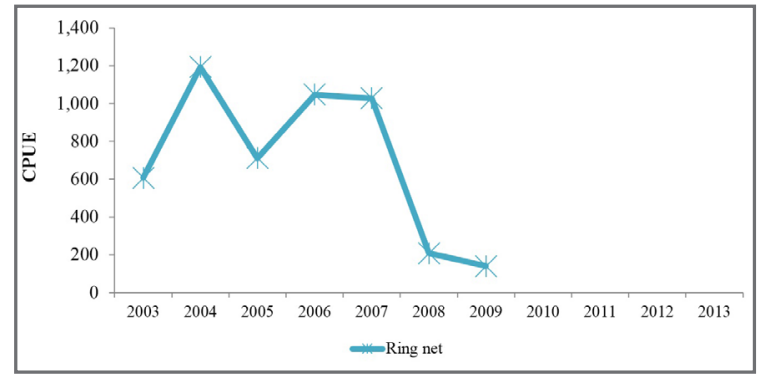

Figure 6. CPUE of commercial gear (ring net) from 2003 to 2009.

For the municipal fisheries, among the four dominant gears, stationary lift net (SLN) has the highest CPUE ranging from $28.0 \mathrm{~kg} /$ boat in 2012 to $75 \mathrm{~kg} /$ boat in 2005. This peak is contributed by the bulk production of Sprateloides robustus for the year which is not commonly appeared in the other years (Figure 7).

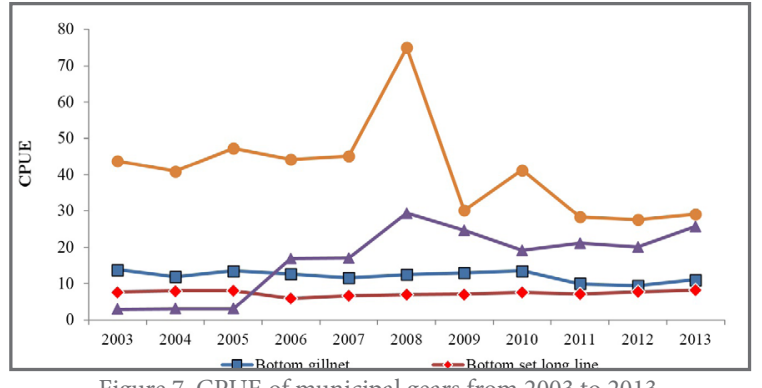

Figure 7. CPUE of municipal gears from 2003 to 2013. 


\section{Species composition}

Catch of Honda Bay is composed of fish and invertebrates families and species.

Ten-year data for the number of fish species recorded an increasing trend from 304 in 2003 to 391 in 2013. These accounts to almost $22 \%$, equivalent to 87 species, and majority of these belong to the family Carangidae (Figure 8). However, for invertebrate families, it shows a fluctuating trend but no significant change in the number is recorded for both the species and families. It ranges from 13 to 22 species (Figure 9).

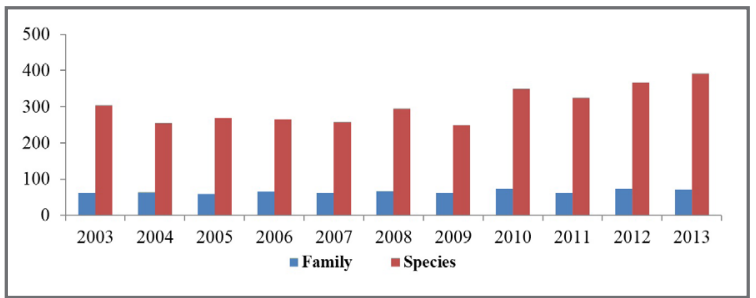

Figure 8. Number of vertebrate families and species identified in Honda Bay from 2003 to 2013.

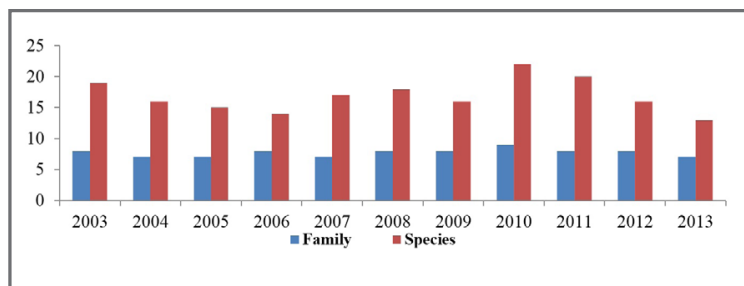

Figure 9. Number of invertebrate families and species identified in Honda Bay from 2003 to 2013.

Most of the species caught recorded from 2003 to 2013 are pelagic fishes with an average percentage of $57.17 \%$, while demersal fishes and reef fishes constitute $28.8 \%$ and $14 \%$ respectively (Figure 9 ). This is attributed to the efficiency of the municipal gears to catch both pelagic and demersal species.

The average number of species identified was observed to be almost the same (302) with Ramos and colleagues in their 1998-2002 study (304). Some families, however, showed an increase in the number of species identified probably due to the efficiency of the gear to catch other targeted species.

In terms of species by family, Carangidae comprises the most which is $9 \%$ of the species caught,

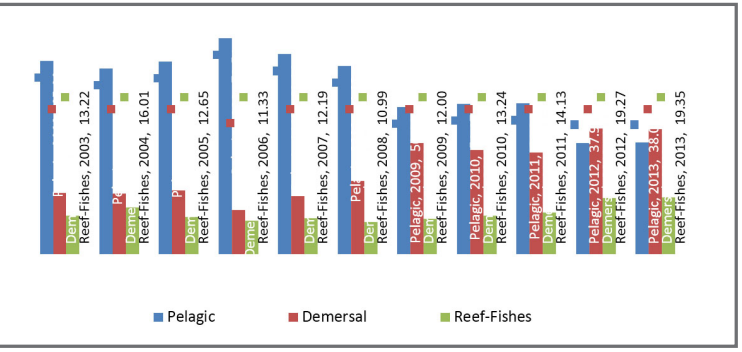

Figure 10. Percentage composition of pelagic, demersal and reef fishes in Honda Bay from 2003 to 2013. with an average number of 57 species dominated by Selar crumenopthalmus, followed by Serranidae (8\%), Lutjanidae (7\%), and Nemipteridae (6\%). The remaining catch which is $79 \%$ were composed of species under the families Lethrinidae, Haemulidae, Mullidae, Labridae, Scaridae, Clupeidae, Leiognathidae, Siganidae, and others (Figure 10).

There were ten families of invertebrates identified. Majority of which were Portunidae which comprised $23 \%$, which is further composed of seven species with Portunus pelagicus as the most dominant (Figure 11).

The catch composition of Honda Bay for commercial fisheries for seven years of operation within the bay were dominated by Amblygaster sirm (39\%) while Emmelichthys nitidus nitidus (1\%) having the least in percentage (Figure 13). For the municipal fisheries, Leiognathus splendens (10\%) dominates while Herklotsichthys dispilonotus (2\%) contributes the least.

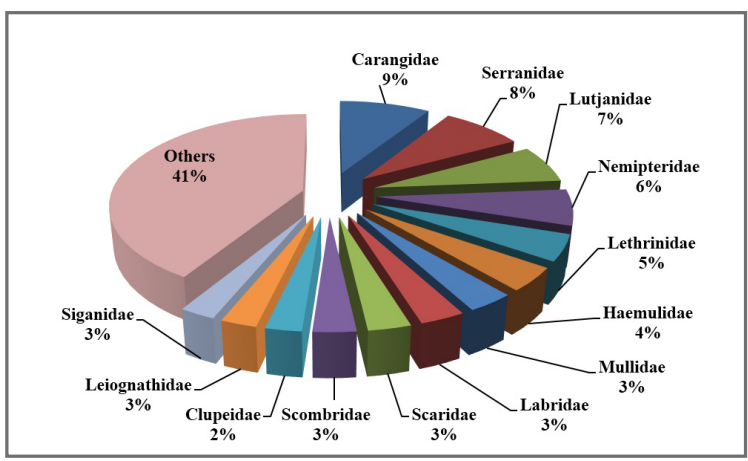

Figure 11. Relative abundance of vertebrate species (by family) caught in Honda Bay from 2003 to 2013.

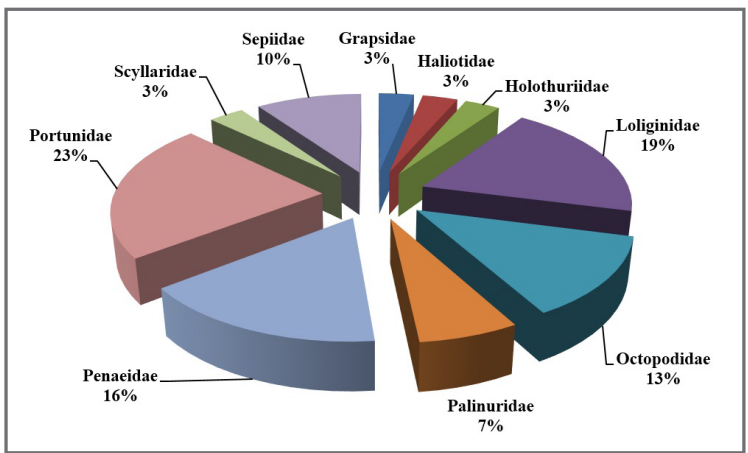

Figure 12. Relative abundance of invertebrate species (by family) caught in Honda Bay from 2003 to 2013.

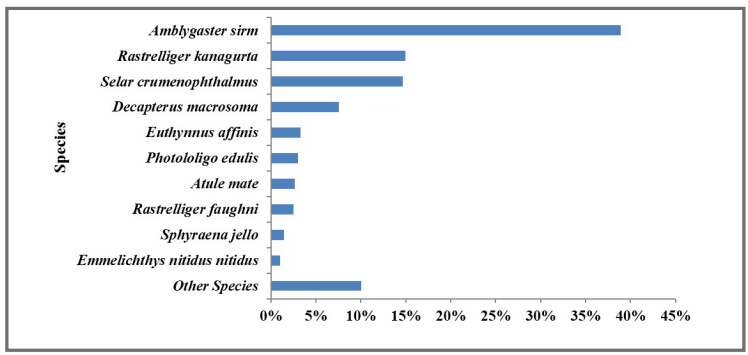

Figure 13. Most abundant species comprising the commercial catch in Honda Bay from 2003 to 2013 
Others were Nemipterus hexodon, Encrasicholina devisi, Octopus dollfusi, Rastrelliger kanagurta, and Gazza minuta (Figure 13). In the study conducted by Ramos et al. (2009), it shows an abundance of Octopus dollfusi which ranks first in 1998 to 2002.

\section{Seasonality of catch}

The trend of production for commercial fisheries operation is influenced by the southwest monsoon, "habagat," from June to October and the northeast monsoon, "amihan," from November to February. So much so that the target species of ring nets are pelagic species which is affected by monsoon winds, rainfall, and plankton biomass (Zaragosa et al. 2004). The peak

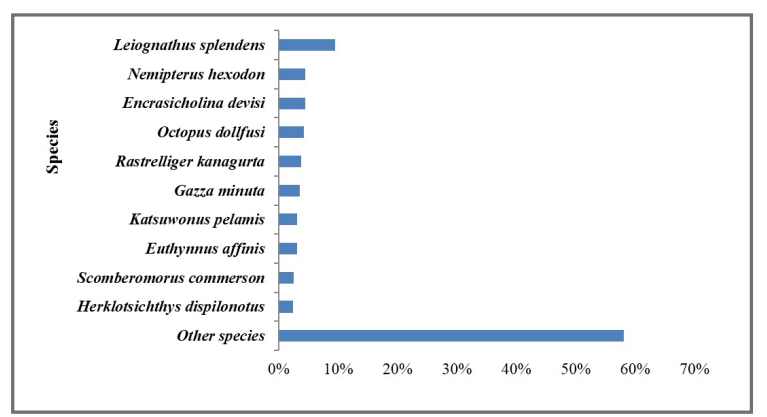

Figure 14. Most abundant species comprising municipal catch in Honda Bay from 2003 to 2013.

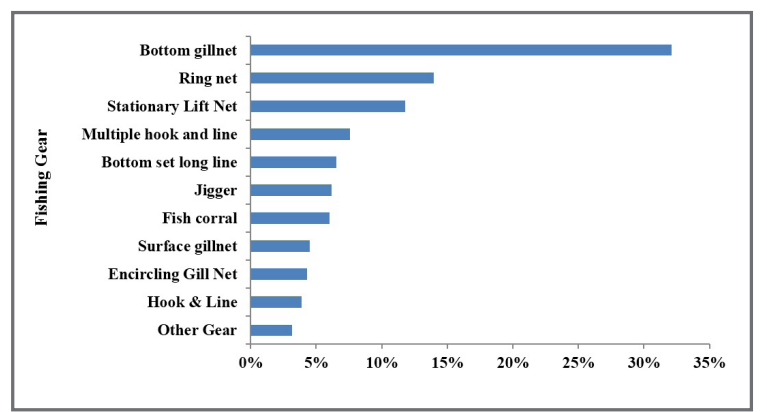

Figure 15. Average share of different types of gear to the total fish production in Honda Bay from 2003 to 2013. of production is noticed during the months of MarchOctober (Figure 18).

The catch of Honda Bay is comprised mostly of ten major gears with BGN having the highest which is $32 \%$ and HL having the lowest contribution of $4 \%$ (Figure $14)$.

Consistent with the study conducted by Ramos et al. (2009), data on catch comparison by gear for the municipal fishery is not pronounced as almost all of the gear operate year round. However, the peak of production is recorded in the first and last quarters of the year (Figures 16-17).

Figure 18 shows the seasonal distribution of four dominant species caught by commercial gears. Amblygaster sirm has its production peak on the months

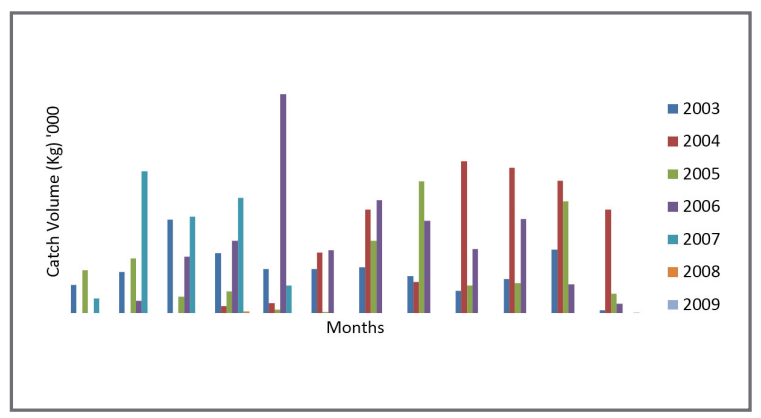

Figure 16. Monthly catch for commercial fishermen in Honda Bay from 2003 to 2013.

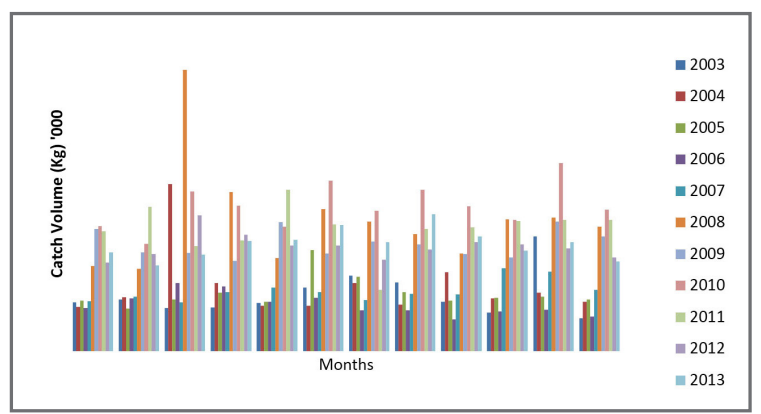

Figure 17. Monthly catch volume for municipal in Honda Bay from 2003 to 2009.

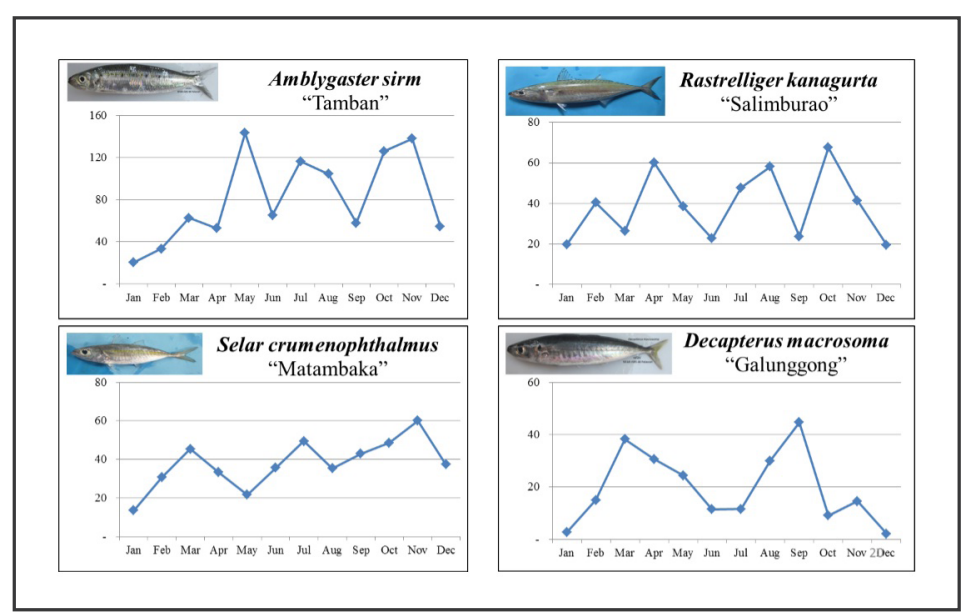

Figure 18. Monthly seasonality of four dominant species of commercial gear in Honda Bay from 2003 to 2013. 
of May to November, Rastrelliger kanagurta is in the months of March, July, and December, and Decapterus macrosoma can be caught in huge volume during the months of March and September.

For the species caught by municipal gears, Leiognathus splendens caught by BGN has its peak during the months of September and December while Nemipterus hexodon is in the months of May, August, and November which is commonly caught by BGN, BSLL, and HL. For Encrasicholina devisi, its production peak is on the months of July and October, while April, June, July, and November are the peak months of Octopus dollfusi caught by Jigger (Figure 19).

\section{Length Frequency Distribution}

For this study, fish corral (FC), encircling gillnet (EGN), and stationary lift net (SLN) caught a high percentage of immature fishes as compared to other types of gear targeting the same.

Among the three major gears catching Atule mate, FC caught the highest percentage of immature fish which is $96.3 \%$ compared to BGN and RN (Figure 20).

For Rastrelliger kanagurta, SLN and FC caught more than $50 \%$ immature as compared to BGN which 9.04\% (Figure 21).

Almost all of the three major gears catch 50\% immature Siganus canaliculatus, however, EGN has the highest which is $77.64 \%$ (Figure 22).

Among the three major gear catching Lethrinus lentjan, EGN caught $93.72 \%$ immature fish with size ranging from 10.5-18.5 cm (Figure 23). For the gear catching Selar crumenphthalmus, SLN caught the highest percentage of immature fish which is $98.81 \%$ while BGN caught $71.05 \%$ and almost $50 \%$ is being caught by $\mathrm{RN}$ (Figure 23-24).

\section{Recruitment pattern}

For 2013 data of species analyzed for recruitment patterns, Selar crumenophthalmus and Rastrelliger kanagurta exhibited unimodal pattern while a bimodal pattern is observed for Siganus canaliculatus and Lethrinus miniatus (Figure 25).

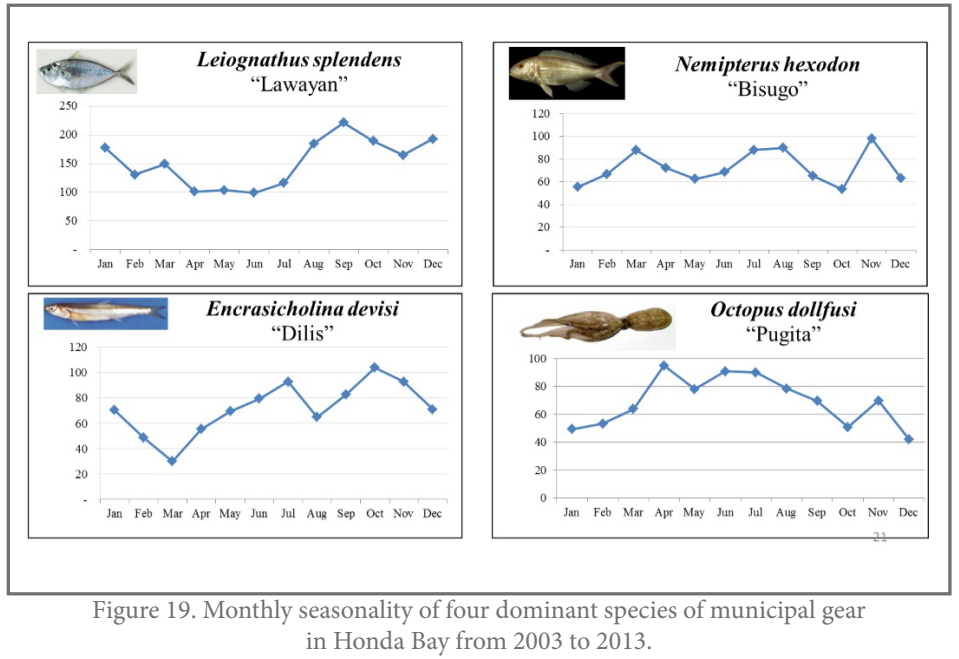

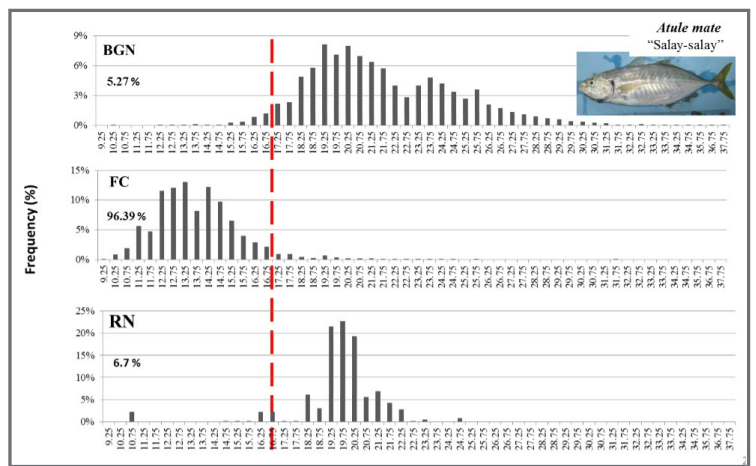

Figure 20. Length frequencies of Atule mate caught by different types of gear in Honda Bay from 2003 to 2013.

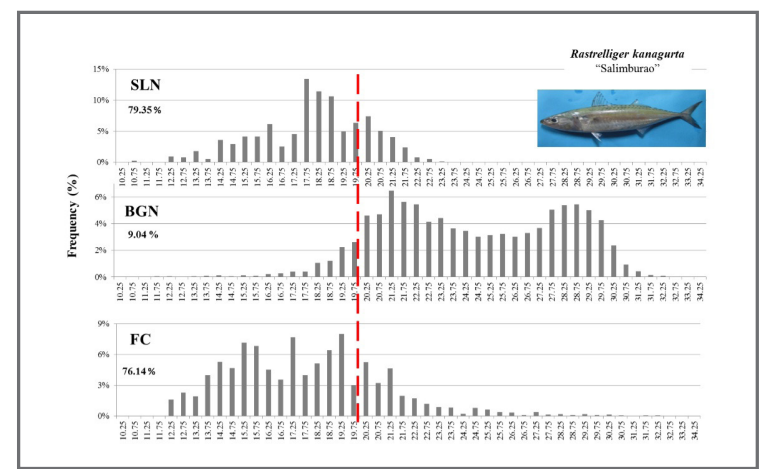

Figure 21. Length frequencies of Rastrelliger kanagurta caught by different types of gear in Honda Bay 2003 to 2013 


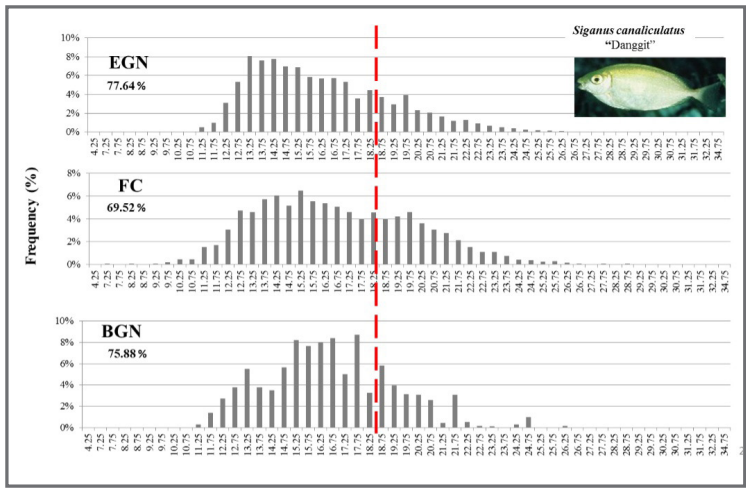

Figure 22. Length frequencies of Siganus canaliculatus caught by different types of gear in Honda Bay from 2003 to 2013.

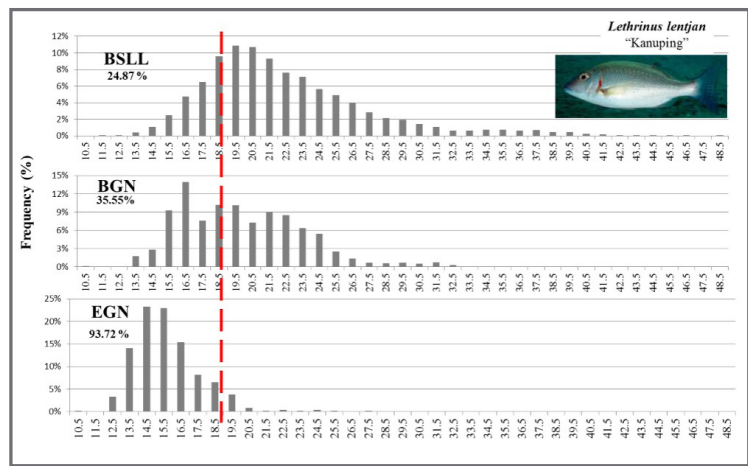

Figure 23. Length frequencies of Lethrinus lentjan caught by different types of gear in Honda Bay from 2003 to 2013.

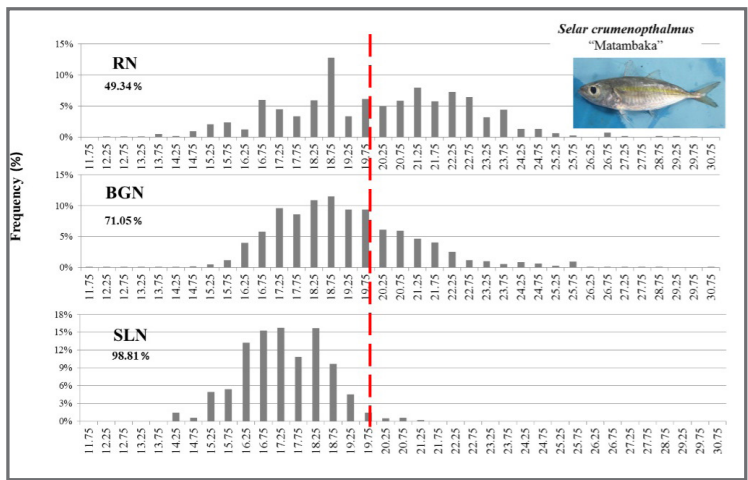

Figure 24. Length frequencies of Selar crumenophthalmus caught by different types of gear in Honda Bay from 2003 to 2013.

\section{Exploitation ratio}

Based on the result of this study, of the 10 species analyzed, the majority have E values above 0.5 , and of the 97 samples, 7\% has estimated $\mathrm{E}$ values which are within the optimum and $93 \%$ are beyond the E value of 0.5 (Figure 26-27). This is an indication that majority of the common species were caught way beyond their regenerative capacity.

\section{Mean Length}

Based on this study, most of the important fish species caught in Honda Bay have a mean size less

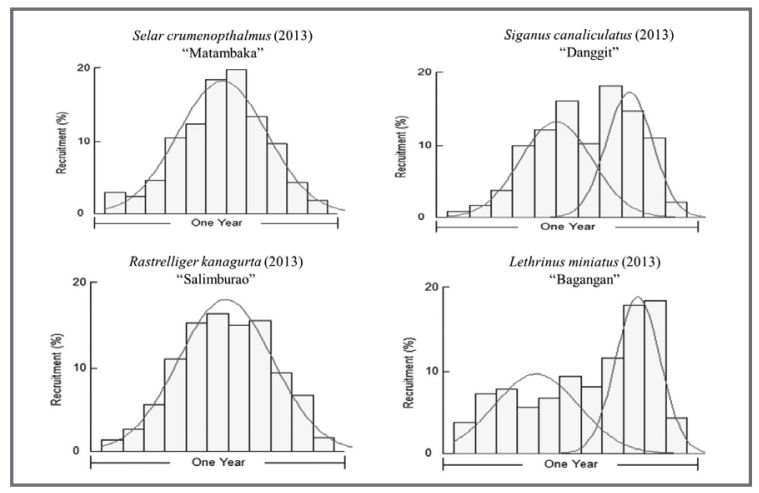

Figure 25. Recruitment pattern analysis of 4 fish species found in Honda bay.

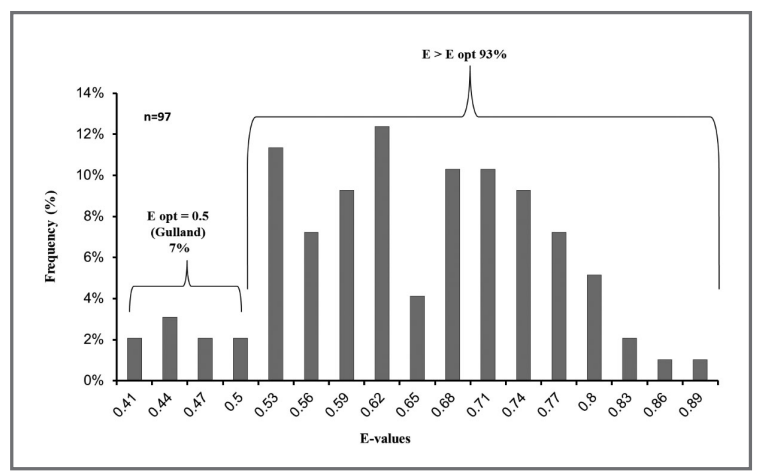

Figure 26. Distribution of E-Values of Common Fish Species (data from 2003 to 2013)

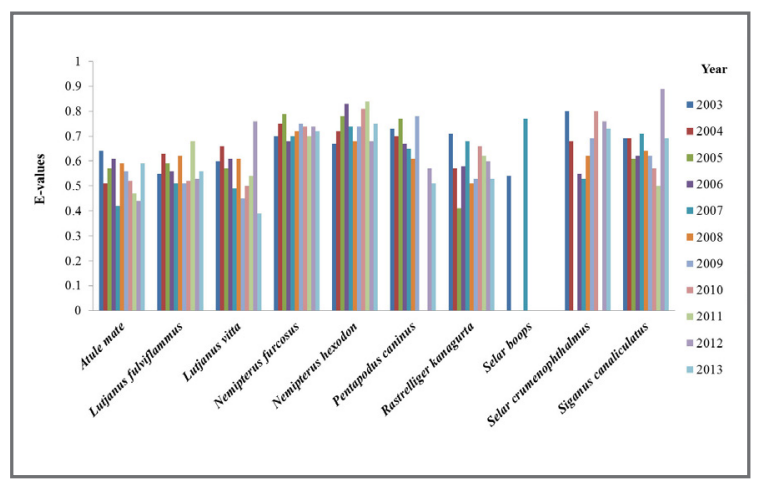

Figure 27. Estimated Exploitation Ratio (E) of Common Species.

than the length at first maturity. This indicates that these species did not contribute to the recruitment process of these stocks before they are caught.

\section{D I S C U S S I O N}

According to Gonzales (2004), Honda Bay is being subjected to increasing resource uses and conflicts due to its central location and growing urbanization and population in the area, resulting in more potential exploitation. Fishers from other regions and municipalities migrate to Honda Bay for greater livelihood prospects. However, some of the gears used in the bay were banned such as the ring net, fish corral with 
compressor, trawl, and spear gun with compressor. Some became too expensive to operate while others simply ceased to be economical.

Honda Bay also became a center of research and assessment by the academe, government institutions, and NGO's. The Resource and Ecological Assessment Vol. I, II, III was also done in the bay in collaboration with BFAR, Asian Development Bank, Japan Bank for International Cooperation SEARCA, and ICLARM. Several BFARFRMP communities have established fish sanctuaries. A handbook on monitoring and evaluation of fish sanctuary is being developed for community-based stakeholders. FRMP seeks the rehabilitation of mangroves as they do to protect the coastline from accretion and serve as a catch basin of water runoff from land. In 2001, there were 46 municipalities with mangrove rehabilitation programs (FRMP 2001 Annual Report).

In addition, the banning of the use of compressor was implemented in the entire Puerto Princesa City, including Honda Bay. The law enforcement in the area became more aggressive and intensified with the help of NGA's NGO's, PO's BFAR, City Government, and Marine Police in implementing the "Bay Watch". Some resort owners and boat operators are also helping to protect the bay. Haribon Palawan and Environmental Legal Assistance Center (ELAC) also provide livelihood projects for the fisherfolks in support to the CBCRM program.

Fishers are now given opportunities to participate in non-fishing activities (i.e. shuttle tourists to resorts) and there is also the implementation of coastal resources management activities (e.g. mangrove reforestation, institutionalization of BFARMCs, establishments of fish sanctuaries in Manalo and Binduyan, etc.). These initiatives contribute to the rehabilitation and increase in diversity, density, biomass, body size and reproductive potential of many species within their boundaries.

A remarkable increase in the number of motorized and non-motorized boats was recorded in 2008 to 2013 same with lines and net gear. Increase in the number of boats and gear was due to the total disappearance of commercial fishing and gear type diversification where fishermen use several types of gear in one fishing operation to augment their income.

Collection of fish and seahorse fry and gleaning in the bay were also recorded.

It can be observed that there is an increase in production from 2008 to 2013 as compared to 2003 to 2007. This is due to the impact of the interventions made by the government on the effective enforcement of fisheries-related laws and the management interventions made by non-government organizations, academe and other institutions, among others, banning the use of active gear, fish corral, trawl and spear gun with compressor, prohibition in the use of obnoxious substance and blast fishing methods and establishment of marine and fish sanctuaries and environmental park. These relieved the bay from high fishing pressures, thereby enriching the natural breeding and feeding ground for marine life.

The same with the result of the study conducted by Ramos et al in 2009, the trend of catch, effort, and catch per unit effort (CPUE) from 2003 to 2013 showed the increased in the number of standard boat landings gives only an increment in catch but with low CPUE. These scenarios attract more fishermen to engaged fishing in the bay and use more efficient gears.

Small, short-lived, and low-priced species of Leiognathidae dominated in the municipal catch and were frequently caught by most of the fishing gear operated in the bay.

Consistent with the study of Ramos et al. (2009), it also noted that the composition of the top ten species in commercial and municipal catch is similar, both consisting mostly of pelagic species, even during the years where no commercial gears is operating in the bay, the same with the results in the composition of relative abundance of species by family except for the existence of family Haemulidae while on this study it was replaced by family Scaridae.

The fishers of the bay commonly identify the position of their fishing ground relative to the location of the various islands. There is a concentration between 30 to $<50$ m depths (RSA 2000-2001). Based on the validation interviews with the fishers and in the landing monitoring, the most visited fishing grounds in the bay are the areas around the islands.

Consistent with the study of Ramos et al. (2009), results of the species analyzed had an estimated value beyond the suggested maximum $\mathrm{E}$ values. This is an indication that the fishery resources of Honda Bay are fully exploited.

Most tropical fish, especially in the Philippines, usually have two recruitment pulses all year round. However, for the seasonal oscillation where the monsoon occurs, the northeast monsoon (November to January) and the southeast monsoon (March to June) will affect the recruitment pulses in that it's either one or two pulses per year (Pauly and Navaluna 1983). According to Carr and Syms (2006), recruitment of larvae or juveniles is important because it is the principal source of population replenishment. Without replenishing the population it will ultimately become extinct (except immigration at small spatial scales). The young of many fishes settle from the pelagic habitat to spend time in "nursery" habitats (Beck et al. 2001) such as estuaries and coastal seagrass and kelp beds (Baskin et al. 2003) before migrating to adult populations, thereby recruiting first to nursery habitats, and adult populations several months later (Gillanders et al. 2003).

\section{C O N C L U S I O N}

The main issue of Honda Bay is the overexploitation of its coastal resources due to excessive fishing, given the current level of fishing effort and exploitation of its coastal fisheries resources as shown in various population parameters. For 10 years its multispecies and multigear condition alleviate to the present situation. Resource competition in the bay is also observed due to the increased number of municipal 
fisheries and low catch constraints, allowing fishermen to use the most efficient gears to increase their profit. Biological overfishing is evident as most of the species analyze exhibits value beyond the suggested maximum $\mathrm{E}$ values, high catch rate per fishers due to high extraction of municipal fishing activities, and a dominance of pelagic species catch even at younger stage by both municipal and commercial gears.

A lot of fisheries administrative orders regarding fish stock conservation had been created to lessen the degree of fishing pressure. This issue may be resolved only if fishery laws are implemented properly, especially in the municipal sector.

\section{ACKNOWLED G M EN T}

The preparation of this book has been made possible through the infinite blessings of our Almighty God, his grace of wisdom and strength.

The authors express their profound gratitude for the administrative and financial support of OICRegional Director of DA-BFAR MIMAROPA Ruben J. Jardin (2003-2015) and Elizer S. Salilig; Mr. Noel C. Barut, Interim Deputy Executive Director of DANFRDI, likewise, for the guidance and moral support of Mr. Roberto R. Abrera, RFRDC Manager, DA-BFAR MIMAROPA.

To Prof. Nygiel B. Armada for assistance and sharing their expertise in data processing and analysis; Ms. Sheryl Mesa, NSAP Project Leader of Region VI; Mrs. Fe Lavipe-Gonzales, Mr. Francisco Torres, and Dr. Mudjekeewis D. Santos, DA-NFRDI Staff.

Gratitude was also extended to, Julius F. Landrito, Amran S. Jaibe, Jonathan T. Bacan, Elmar M. Villaflor, Annielyn C. Delgado, and Adzel Adrian G. Baldevieso, for their untiring effort in encoding, data processing, and consolidating; to the NSAP Enumerators, Arlyn A. Echague, Jeffrey E. Cuaresma, Gemma V. Timbancaya, Rommel M. Gabo, Ariel F. Bonbon, Santiago G. Libarra, Alvin M. Ignacio, Raffy R. Perez, Rachel J. Lita, and Rachelle Ann Delfin, who bravely face the unexpected challenges in order to perform their responsibility as data gatherers. And to all fishermen, fishing boat crews, and captains on the various landing centers monitored by this project for their continuous support and cooperation in this study.

\section{RE FER E N C E S}

Baskin Y, Beck MW, Heck KL, Able KW, Childers DL, Eggleston DB, Gillanders B, Halpern BS, Hays CG, Hoshino K, Minello TJ, Orth RJ, Sheridan PF, and Weinstein PM. 2003. The role of nearshore ecosystems as fish and shellfish nurseries. Issues Ecology. 11:1-12

Beck MW, Heck KL, Able KW, Childers DL, Eggleston DB, Gillanders BM, Halpern B, et al. 2001. The identification, conservation, and management of estuarine and marine nurseries for fish and invertebrates. Biosci. 51: 633-641.

Carr M, Syms C. 2006. Recruitment In: The Ecology of Marine Fishes: California and Adjacent Waters. 2006. L.G. Allen, D.J. Pondella, and M. H. Horn (eds.). University of California Press, Berkeley, p. 670 .

Conand F. 1991. Biology of Amblygaster sirm (Clupeidae) in new Caledonia, A sardine of the Coral Environment. Bulletin of Marine Science. 48(1): 137-149.

Gayanilo FC. Jr, Sparre P, Pauly D. 1995. FAO-ICLARM Stock Assessment Tools (FiSAT) User's Manual. FAO Comp. Info. Ser. (Fisheries) 8, p. 126.

Gillanders BM, Able KW, Brown JA, Eggleston DB, Sheridan PF. 2003. Evidence of connectivity between juvenile and adult habitats for mobile marine fauna: an important component of nurseries. Mar. Ecol. Prog. Ser 247: 281-295

Gonzales BJ. 2003. Puerto Princesa Bay and Honda Bay, Palawan: An Ecological Profile. Tech. Monogr. Ser. No. 8. Fisheries Resource Management Project, DABFAR

Gonzales, B. J. 2004. Fisheries Management in Honda Bay, p. 305-311.

Hermes JE. 1998. Fish Processing in the Tropics, Tawid Publications, ISBN 971 91395-7-9, Quezon City, Philippines.

Lachica-Aliño L, Sariego R, Montaño B, Desabelle E, H. Palla, R. Creador and G. T. Silvestre. 2001. Results of the Fish Stock Assessment of Honda Bay, Palawan (2000-2001). Resource and Social Assessment of Honda Bay and Puerto Princesa Bay. Fisheries Resource and Management Project, Philippines.

Palawan Council for Sustainable Development (PCSD). 2008. Conservation of a Natural Heritage: Estimating Non-Use Value of Honda Bay in Palawan, Philippines.

Pauly D, Munro JL. 1984. Once more on the comparison of growth in fish and invertebrates. Fishbyte 2(1): 21.

Puerto Princesa City Ordinance No. 163. 2004. An ordinance revising the zoning regulations of the City of Puerto Princesa and providing for the administration, enforcement, and amendment thereof and for the repeal of all ordinances in conflict therewith.

Ramos MH, Candelario MB, Mendoza EM, Gonzales FL. 2009. The Honda Bay Fisheries: An Assessment, BFAR-NFRDI Technical Paper Series Vol. 12, No. 2, p. 45. 